only by a broad and integrated range of health and social services. The principles espoused by Reed are that high quality care should be provided by health and social services (not in the criminal justice system) according to individual need, near to the patient's home or family, as far as possible in the community but otherwise in conditions of no greater security than is justified; the ultimate aim should be to maximise rehabilitation or opportunities for independent living.

A multiagency approach and local ownership of services are seen as crucial. Most mentally disordered offenders should be cared for by general psychiatry and learning disability services, with access to more specialised resources when necessary. There should be an expansion, and wider range, of community based facilities. A stronger academic and research base should be established to underpin developments and play a key part in training.

The Reed report has profound implications for the government, patients, doctors, and managers. The government must decide what it will accept and fund. The report is impressive because it is comprehensive. It cannot be implemented in whole overnight. (Where, for example, are 175 new psychiatrists and 80 forensic psychiatrists to be found?) But its recommendations are interdependent, and large chunks cannot simply be jettisoned. For example, what use are the 900 extra places in regional secure units proposed by Reed if there are no appropriate facilities for aftercare? What value is a nationwide system of court diversion schemes if there are no beds to which patients can be diverted?

The chief implication for patients is that they should not be disadvantaged by their status as offenders. General practitioners and psychiatrists will need to accept that at times some mentally disordered patients may be violent, for that is the nature of serious mental disorder whether in patients suffering their first episode of schizophrenia, ${ }^{6}$ long stay patients newly settled in the community, ${ }^{7}$ or mentally ill residents in hostel accommodation. ${ }^{8}$ These patients do not forfeit their entitlement to care by manifesting features of their illness.

The Reed report will tax the ingenuity of managers in the NHS and in local authorities. It has not priced its recommendations, but emphasises the need to consider the costs to all agencies of "misplaced" patients and the costs incurred by denying early intervention. It emphasises the pernicious financial disincentives that influence agencies to deflect responsibility for mentally disordered offenders. Such a patient in prison or special hospital costs a district health authority nothing. It therefore proposes that each district health authority should accept financial responsibility for all the health care needs of its mentally disordered offenders (in common with the rest of its citizens) even if they are receiving specialist treatment outside the authority's boundary. In planning services, NHS managers will need to work closely with general practitioners, local authorities, and agencies in the voluntary sector and criminal justice system. Regional health authorities, too, have crucial roles in conducting assessments of need, ensuring the provision of services, and monitoring standards.

Is it possible at this early stage to spot any green shoots of growth in services? The government would point to some pilot projects to divert people from court and to its increase in capital funding for medium secure facilities for 1992-3. It has also announced the establishment for three years of a national advisory committee to follow up action on the Reed report. On the negative side, $53 \%$ of purchasers and $54 \%$ of providers recently surveyed by Blumenthal and Wessely had no current or future plans for schemes to divert people from courts. ${ }^{9}$

Can the massive exercise in multiagency working which Reed proposes be implemented? It comes at a time of economic recession and when agencies are struggling with new funding arrangements and new roles. Some, such as the regional health authorities, face an uncertain future. ${ }^{10} \mathrm{We}$ can see clearly the requirements for mentally disordered offenders, and Reed has done a masterly job in presenting them. But will the operation get afloat? Or will complex bureaucracy, the market economy in the NHS, and inadequate funding leave it dead in the water? We must hope not.

Consultant Forensic Psychiatrist,

DEREK CHISWICK

Royal Edinburgh Hospital,

Edinburgh EH10 5 HF

1 Department of Health. The health of the nation. London: HMSO, 1992. (Cm 1986).

2 Department of Health, Home Office. Review of health and social services for mentally disordered offenders and other requiring similar services. Final summary report. London: HMSO, 1992. (Cm 2088).

3 Dillner L. Mentally disordered offenders need care, not imprisonment. BMF 1992;305

4 Chiswick D. What mentally ill offenders need. BMF 1992;304:267-8.

5 Welsh Office. Report of the all-Wales advisory group on forensic psychiatry. Cardiff: Welsh Office, 1992.

Humphreys M, Johnstone E, MacMillan J, Taylor P. Dangerous behaviour preceding firs admissions for schizophrenia. Br f Psychiatry 1992;161:501-5.

Dayson D, Gooch C, Thornicroft G. The TAPS project. 16. Difficult to place, long term psychiatric patients: risk factors for failure to resettle long stay patients in community facilities. $B M f$ 1992;305:993-5.

Marshall M, Gath D. What happens to homeless mentally ill people? Follow up of residents of Oxford hostels for homeless. $B M \mathcal{F}^{1}$ 1992;304:79-80.

Blumenthal S, Wessely $S$. National survey of current arrangements for diversion from custody in England and Wales BMF 1992;305:1322-5.

10 Ham C. What future for the regions? BMF 1992;305:130-1.

\title{
A national standard for entry into general practice
}

\author{
Practical and symbolic benefits
}

A national standard of entry into general practice-under consideration by the Joint Committee on Postgraduate Training for General Practice 1 - has important implications for all of general practice but particularly for vocational training. It puts general practice on the same footing as other specialties.

If the recommendations of the working party set up to advise the joint committee are accepted, then knowledge, performance during consultations, practical and management skills, and ability to audit will be taken into account together with trainers' overall assessments. No final summative assessment (end point assessment with set standards) has yet been agreed, but, if a standard for entry is to be set and a certificate which determines competence awarded, it is hard to avoid the need for one.

Knowledge is best assessed by multiple choice or modified essay questions; why the working party thought that this should be set and applied locally is hard to fathom. The multiple choice questionnaire and written component of the examination for the MRCGP are already accepted by most trainees, academic departments of general practice, and general practice partnerships as a national standard of written knowledge. ${ }^{2}$ The examination's timing and purpose as an end 
point assessment have been questioned, ${ }^{3}$ but as a base of factual knowledge it is accepted. Its failure rate of about $26 \%$ may be, however, too high to identify those few trainees who cannot or will not attain a certificate of competence.

Skills and attitudes are more difficult to assess. Performance during consultations, whether observed directly or by video or assessed by analysis of random cases, should be carried out by a trainee's trainer. Because no single method can provide all the information that is needed ${ }^{+}$the joint committee has previously recommended a wide range of assessment methods, including the Manchester rating scales. ${ }^{5}$ These are regularly used nationally and internationally to assess individual trainees' knowledge and educational needs (formative assessment).$^{6-11}$ If the new Manchester rating scale is applied correctly for formative assessment it needs to be used three times during a traineeship, and each time takes up a day and a half of the trainer's and trainee's time.

A summative assessment would take longer, especially if an outside assessor was involved. Setting standards for a summative assessment has so far eluded any committee or region; with the changing role of principals in general practice its content would have to change continually. One suggestion has been to use a condensed version of the Manchester rating scale: one low rating or several poor ratings would be grounds for refusing certification." Whatever standards are set, they must be valid, practicable, and acceptable to the profession and of proved reliability. Trainers in the west of Scotland have made great strides in this direction."

Trainers' assessments of their trainees are not always reliable owing to the "halo effect" and their variation from trainer to trainer. It has been suggested that, because formative assessment addresses the strengths and weaknesses of trainees throughout their training, eventually a summative assessment will not be necessary. Unfortunately, the Australian model of formative assessment was deemed insufficient to guarantee quality. ${ }^{12}$

Currently two thirds of vocational training takes place in hospital posts; more thought needs to be given to its assessment, especially when time in so many specialties counts as relevant experience. One solution-explaining assessment to consultants-yielded benefits in the Northern region, but more than 20 years after vocational trainee schemes were set up the time has come to question the relevance of hospital senior house officer posts.

Intensive and invasive hospital medicine differs greatly from the same subject in general practice: the care of pregnant women, children, and patients with diabetes and asthma (to name just a few) could and should be taught and assessed in general practice. The introduction of assessment could be a springboard to increase the time spent in general practice to two years-either by reversing the present division of two years in hospital posts and one year in general practice or by increasing vocational training to four or five years. Both these arrangements would provide several years of formative assessment in general practice by general practice.

A longer vocational training and a summative assessment also fit well with suggestions made by the working party of the Royal College of General Practitioners on higher education. These would result in the following career path after qualification: preregistration posts; vocational training and assessment diploma; young principal and MRCGP; higher professional education (leading to $\mathrm{MD}$ or $\mathrm{MSc}$ ); and, finally, continuing medical education and FRCGP. ${ }^{13}$

Whatever form of assessment is adopted, some doctors will fail, which the working party acknowledges. ${ }^{12}$ It suggests that additional training and counselling will remedy this, but some: trainees-either through lack of knowledge or volition of ${ }^{5}$ through personality problems-will probably never reaclf such a standard. Consideration should therefore be given to career grade post for practitioners who will never achieve the status of principals.

Trainees need not feel threatened by these suggestions They already undergo several assessments during training.? Further formative assessment can only strengthen thei $\vec{\omega}$ personal educational programme, and summative assess $\frac{\text { s }}{\partial}$ ment, which most $(70 \%)$ now seek in the MRCGP, will give sense of achievement.

Creating a national standard of accreditation will $\cos \overbrace{\pi}$ money and take much hard work to give it credibilityo Through the General Medical Services Committee and the Royal College of General Practitioners vocational trainings should be lengthened and strengthened: formative ando summative assessment should become an integral part of every trainee's education.

General Practice Trainer,

TIM CARNEYO

Burn Brae

Hexham,

Northumberland NE46 2ED

1 Joint Committee on Postgraduate Training for General Practice, Working Party on AssessmenN

The interim repon of the working party on assessment. London: JCPTGP, 1992.
Royal College of General Practitioners. Quality in general practice. London: RCGP, 1985. (Polic statement 2.)

3 Roberts G. Timing and purpose of the MRCP examination. I R Coll Gen Pract 1989;39:30-1.

4 Joint Committee on Postgraduate Training for General Practice, Assessment Working Part Report. London: JCPTGP, 1987.

Centre for Primary Care Research, Department of General Practice, University of Mancheste Rating scales for vocational training in general practice. London: RCGP, 1988. (Occasion@ paper 40.)

6 Difford $\mathrm{F}$, Hughes RCW. Experience of using rating scales for the assessment of vocational traine in general practice. Br f Gen Pract 1991;41:360-4

Hays RB. Assessment of general practice consultations: content validity of a rating scale. Med Edw 1990;24:110-6.

8 Campbell I.M, Murray TS. Trainee assessment-a regional survey. Br f Gen Pract 1990;40 $507-9$.

9 Cunningham B. Report of the Northern region working group on rating scales. Post Gradua Education for General Practice 1992;3:142-6.

10 Pendleton D, Schofield T, Tate P, Havelock PP. The consultation. Oxford: Oxford Universio Press, 1984

1 Middleton J. Methods of assessment. Horizons 1991;5:75-8.

12 Mulholland H, Tombleson PMJ. Assessment of the general practitioner. Br 7 Gen Prae 1990;40:252-4

13 Pietroni R. New strategies for higher professional education. Br f Gen Pract 1992;42:294-6.

Correction

\section{Viral diarrhoeas in childhood}

An author's error occurred in this editorial by Elisabeth J Elliott (7 Novembef pp 1111-2. The last sentence in the penultimate paragraph should read, "Opioid (for example, the diphenoxylate hydrochloride component of Lomotil) may cau\& respiratory depression and even death," not "Atropine-like drugs may caus respiratory depression and even death," as published. 